\title{
Creep Deformation and Fracture Behaviors of Ultra-Purified Ferritic Stainless Steel 429Mo With Nb and Ti Dual Stabilization
}

\author{
Cai-Hong YING ${ }^{1,2, a,{ }^{*},}$ Tian-Long LIU ${ }^{1, b}$, Li-Jia CHEN ${ }^{1, c}$ and Lian-Quan GUO ${ }^{2, d}$ \\ ${ }^{1}$ School of Materials Science and Engineering, Shenyang University of Technology, Shenyang \\ 110870, China \\ ${ }^{2}$ School of Science, Shenyang University of Technology, Shenyang 110870, China \\ arainbow-anna@163.com, 'lt|_0508@hotmail.com, chenlj-sut@163.com, 'guo_lq@163.com
}

Keywords: Ultra-purified ferritic stainless steel, Dislocation climb, Creep resistance, Transgranular fracture

\begin{abstract}
In order to clarify the creep deformation and fracture behaviors of ultra-purified ferritic stainless steel $429 \mathrm{Mo}$ for automotive exhaust systems, the creep behaviors of $429 \mathrm{Mo}$ steel at $650^{\circ} \mathrm{C}$ and different applied stress levels were investigated through performing the creep tests and the microstructural observation after creep tests. The results show that the applied stresses have obvious effect on the creep behavior. With increasing the applied stress, the minimum creep rates increase and fracture lives decrease. The creep stress exponent of 4.22 and the observed microstructure indicate that a dislocation climb creep mechanism controls the creep deformation. The second-phase particles as well as the stable sexangle and quadrangle dislocation networks are helpful to improve creep resistance. The creep test data follow the Monkman-Grant relationship and Larson-Millar relationship, which can also be used to predict the creep lifes. The predicting result of the former is more accurate. Both macrographs and micrographs of fracture surfaces indicate that the creep fracture mode is ductile transgranular fracture for the $429 \mathrm{Mo}$ steel.
\end{abstract}

\section{Introduction}

Compared to austenitic stainless steels, ferritic stainless steels have many advantages, such as good resistance to pitting, low coefficient of thermal expansion and high oxidation resistance. Morever, ferritic stainless steels have good enconomic values due to no nickel or little nickel which is expensive and rare. With the progress in the steel metallurgical techniques, the ultra-purified ferritic stainless steels with extra-low carbon and nitrogen $\left(\leq 150 \times 10^{-6}\right)$ as well as the optimized alloy element contents have been developed, which have more benefits such as the improved surface quality, better formability and weldability, better creep resistance and thermal fatigue resistance, better aqueous corrosion resistance[1-5]. At the present, the ferritic stainless steels have been used widely in automobile industry, especially haust systems [6,7]. Automobile haust systems are frquently exposed in long-term elevated temperature and suffer to the creep damage which directly influences the usage life of such components. Therefore, it is necessary to pay more attention to the creep behaviors of ferritic stainless steels. $\mathrm{Nb}$ is a ferrite-stabilizing element and all kinds of precipitates such as $\mathrm{Nb}(\mathrm{C}, \mathrm{N}), \mathrm{Fe}_{2} \mathrm{Nb}$ (Laves phase) and $\mathrm{Fe}_{3} \mathrm{Nb}_{3} \mathrm{C}$ are formed when $\mathrm{Nb}$ is added in ferritic stainless steels [8-12]. $\mathrm{W}$ is an element which is potentially suitable to impart the solid solution strengthening effect. The combined additions of $\mathrm{Nb}$ and $\mathrm{W}$ can increase the creep resistance of ferritic steels $[13,14]$. It is reported by Chiu et al. $[14,15]$ that the creep property of Crofer $22 \mathrm{H}$, which is a ferritic stainless steel by adding $\mathrm{Nb}$ and $\mathrm{W}$ into Crofer 22APU with Ti stabilization, can be improved. Such improved creep resistance in the Crofer $22 \mathrm{H}$ steel can be attributed to a precipitation strengthening effect of fine Laves phase $(\mathrm{Fe}, \mathrm{Cr})_{2}(\mathrm{Nb}, \mathrm{W})$ which is not found in the 22APU. Meanwhile, the extent of improvement is reduced due to the coarsening effect of precipitates. However, the studies about the creep behaviors of ferritic stainless steels are very limited in the literature, and can not give full interpretations about the essence of creep.

The 429Mo steel is a new-type ultra-purified ferritic stainless steel with $\mathrm{Nb}$ and $\mathrm{Ti}$ dual stabilization, and is used widely in automobile exhaust systems. The aim of the current work is to 
study the creep deformation and fracture behaviors of $429 \mathrm{Mo}$ steel at $650^{\circ} \mathrm{C}$ and different applied stresses in order to provide a basis for the reasonable use of ferritic stainless steels.

\section{Experimental Procedures}

The material used in the present study is a commercial 429Mo ferritic stainless steel with the chemical composition (wt. \%) of $\mathrm{Cr} 15$, Mo 0.5, Nb 0.45, Ti 0.3, $\mathrm{C} \leq 0.030, \mathrm{~N} \leq 0.020, \mathrm{Ni} \leq 0.3$, $\mathrm{Mn} \leq 1.2, \mathrm{Si} \leq 1.2$ and Fe balance. The material is provided by Baosteel in the form of plate with $16 \mathrm{~mm} \times 8.0 \mathrm{~mm} \times 1.7 \mathrm{~mm}$. The yield strength and ultimate tensile strength of $429 \mathrm{Mo}$ steel at $650^{\circ} \mathrm{C}$ are $154.80 \mathrm{MPa}$ and $271.05 \mathrm{MPa}$, respectively.

The geometry of creep specimen used in this investigation is shown in Fig. 1. The constant-load creep tests were performed on GWT304 creep test machine in the laboratory environment. The test temperature was $650^{\circ} \mathrm{C}$, and the imposed stresses were ranged from 60MPa to 80MPa. All creep tests were performed to final creep fracture. Both creep strain-time curves and creep rate were gained based on the creep test data. The morphologies of creep fracture surface were observed with scanning electron microscope (SEM). Transmission electron microscope (TEM) was used to observe the microstructures. The thin foils for TEM observation were cut paralleled to the longitudinal direction of creep specimen and prepared with a twinjet polishing technique.

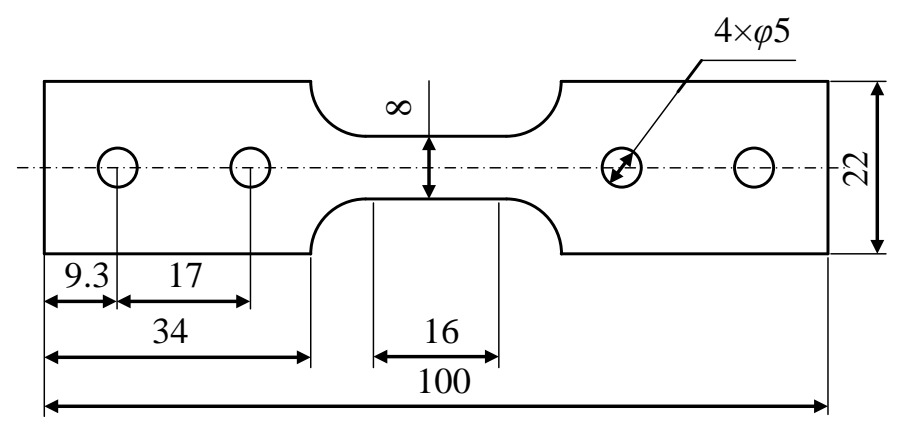

Fig. 1 Geometry of creep specimen [unit: mm]

\section{Results and Discussion}

Fig. 2 shows the creep stain-time curves of $429 \mathrm{Mo}$ ferritic stainless steel at $650^{\circ} \mathrm{C}$. At different applied stresses, the shape of creep curves is similar. All curves include three stages, i.e., primary creep stage, steady state creep stage and accelerated creep stage. Moreover, the primary creep stage where the creep rate decreases with time are relatively shorter, while the steady state and accelerated creep stages are longer. Obviously, the creep deformation of 429Mo steel is dominated by the latter two stages. As shown in Fig. 2, the minimum creep rate increases and the creep fracture lives decrease with an increase in the applied stresses. When the applied stress is 60MPa, the minimmum creep rate is $2.77 \times 10^{-4} \mathrm{~h}^{-1}$ and the fracture life is $130.9 \mathrm{~h}$. When the applied stress is $70 \mathrm{MPa}$ and $80 \mathrm{MPa}$, the minimum creep rates reach to $6.06 \times 10^{-4} \mathrm{~h}^{-1}$ and $10.3 \times 10^{-4} \mathrm{~h}^{-1}$, and the creep fracture lives significantly decrease to $42.8 \mathrm{~h}$ and $31.4 \mathrm{~h}$, respectively.

It is well known that the dependence of the temperature $T$ and applied stress $\sigma$ on the minimum creep rate $\dot{\varepsilon}_{\min }$ for most metals can be described by eq. 1 .

$$
\dot{\varepsilon}_{\text {min }}=A \sigma^{n} \exp \left(-\frac{Q}{R T}\right) .
$$

where $A$ is the constant relevant to materials, $n$ is the stress exponent, $Q$ is the apparent activation energy, and $R$ is the universal gas constant. It is obvious that at the given temperature, the relationship between $\lg \dot{\varepsilon}_{\text {min }}$ and $\lg \sigma$ is linear. 
Fig. 3 illustrates the relationship between the minimum creep rate and applied stress for 429Mo steel at $650^{\circ} \mathrm{C}$. It can be derived from the slope of fitted straight line that the stress exponent of 429Mo steel under the present test condition is 4.22. The value of stress exponent $n$ can represent the mechanism which controls the creep deformation. A value of $n$ in the range from 3 to 8 indicates a dislocation type of creep mechanism [16]. In the present work, $n$ equal to 4.22 indicates that for the $429 \mathrm{Mo}$ steel, the creep mechanism at $650^{\circ} \mathrm{C}$ is the dislocation-climb mechanism. It means that the creep mechanism of $429 \mathrm{Mo}$ steel is the same as that of ferritic stainless steel Crofer 22 APU [15].

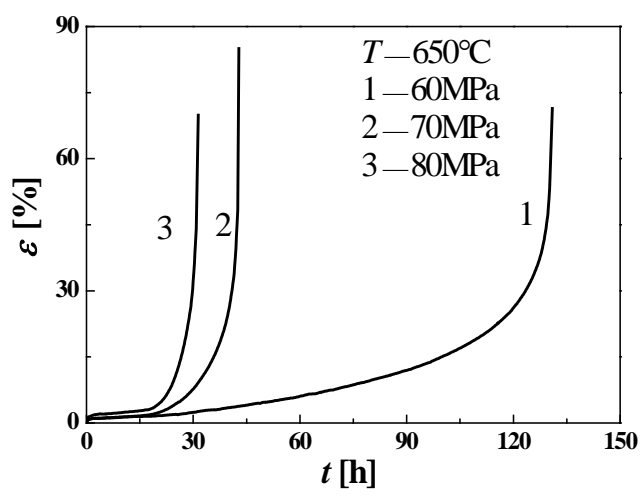

Fig. 2 Creep stain-time curves of $429 \mathrm{Mo}$ steel at $650^{\circ} \mathrm{C}$



Fig. 3 Relationship between minimum creep rate and applied stress for $429 \mathrm{Mo}$ steel at $650^{\circ} \mathrm{C}$

It is generally recognized that the creep deformation includes two processes, where one is the production of new dislocations and the inhibition of dislocation movement by obstacles, and the other is the escaping of dislocations from obstacles and the continuing movement of dislocations. The former leads to an increase in the creep rate, while the latter will result in the decrease of creep rate. Meanwhile, the interaction between the dislocations and second-phase particles in the alloys can decrease the creep rate. The microstructures of 429Mo ferritic stainless steel after the creep at $650^{\circ} \mathrm{C}$ and different stresses are shown in Fig. 4. There are a large number of the second-phase particles precipitated during the creep, which can pin the grain boundaries and keep the grain boundary from sliding. In addition, the dislocations pile up and tangle around the precipitates and form both sexangle and quadrangle dislocation networks, as shown in the Fig. 4(a) and (c). Such regular dislocation networks are very stable and result in the improved creep resistance. Some parallel dislocation lines and dislocation jog are found in Fig. 4(b) and (d), as indicated by the arrows. The dislocation-climb creep mechanism of 429Mo steel under the present test condition gets further confirmed.

Generally, the relationship between the minimum creep rate $\dot{\varepsilon}_{\min }$ and the fracture time $t_{\mathrm{f}}$ can be represented with Monkman-Grant (M-G) relationship.

$$
\dot{\varepsilon}_{\min }^{m} \cdot t_{\mathrm{f}}=C .
$$

where $m$ is constant which is approximate to 1 , and $C$ is the named M-G constant when $m=1$. As soon as this relation is established from the short-term tests, it can be used to predict the long-term creep fracture life if the minimum creep rate is obtained. Fig. 5 shows the double logarithmic relationship between the minimum creep rate and the fracture life of $429 \mathrm{Mo}$ steel at $650^{\circ} \mathrm{C}$. Thus, the $\mathrm{M}-\mathrm{G}$ relationship can be expressed by eq. 3 .

$$
\dot{\varepsilon}_{\text {min }}^{1.22} \cdot t_{\mathrm{f}}=0.0058 .
$$

At present, this method of predicting creep fracture life has been studied in many stainless steels [17, 18]. The predicted creep fracture lives of $429 \mathrm{Mo}$ steel at the different applied stresses are listed in Table 1. 

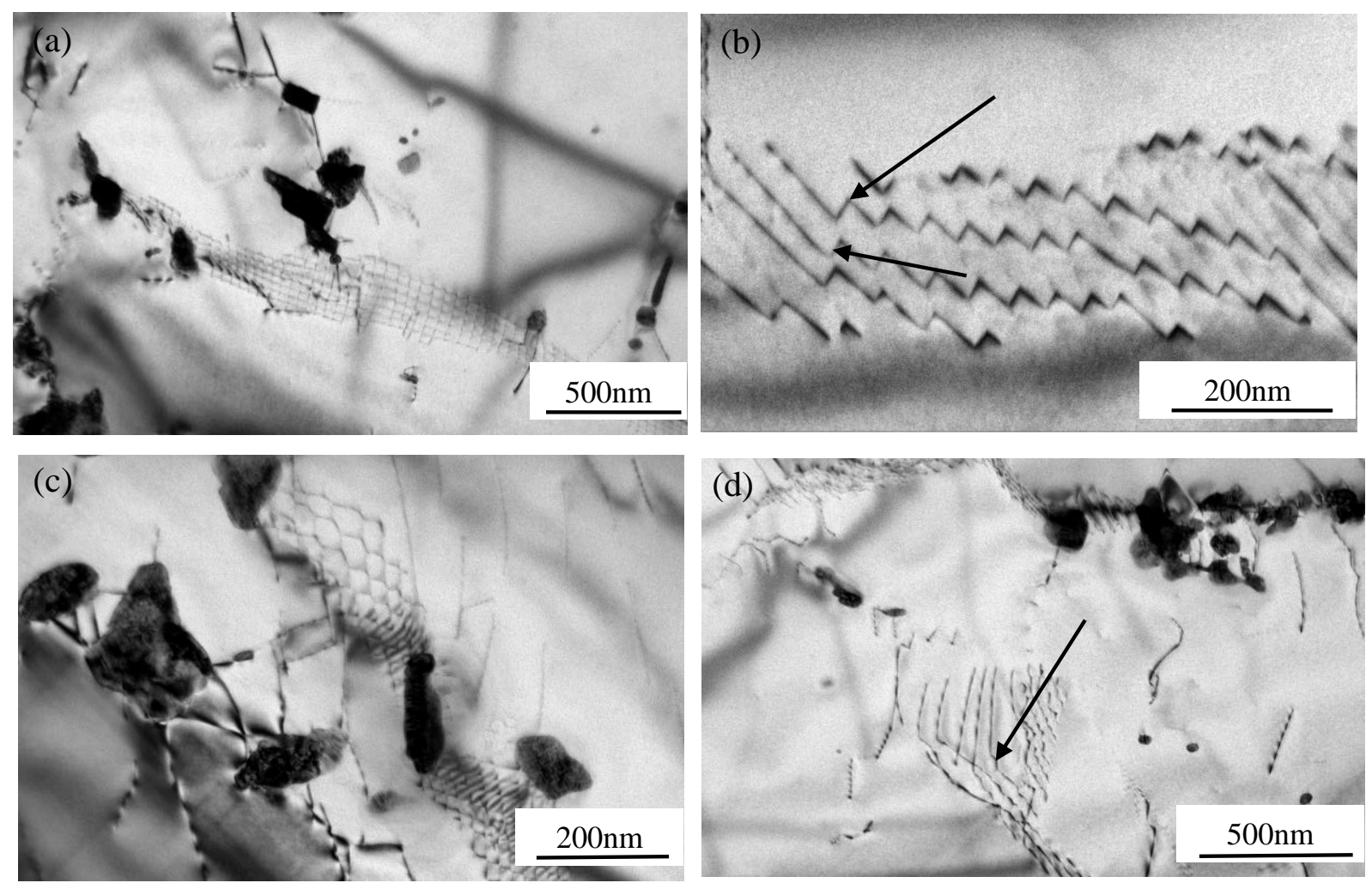

Fig. 4 Microstructures of $429 \mathrm{Mo}$ ferritic stainless steel after creep at $650^{\circ} \mathrm{C}$

(a) and (b) 60MPa; (c) and (d) 80MPa

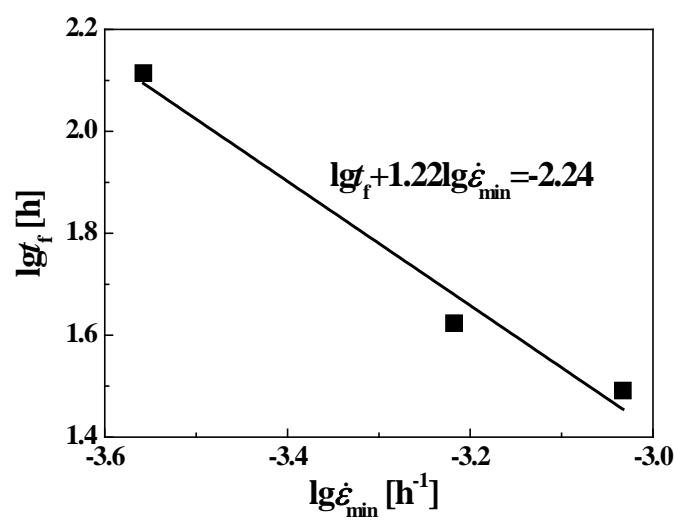

Fig. 5 Relationship between minimum creep rate and fracture life of $429 \mathrm{Mo}$ steel at $650^{\circ} \mathrm{C}$



Fig. 6 Relationship between applied stress and $P_{\mathrm{LM}}$ for $429 \mathrm{Mo}$ steel at $650^{\circ} \mathrm{C}$

Table 1 Predicted and measured creep fracture lives for 429Mo steel

\begin{tabular}{llll}
\hline $\begin{array}{l}\text { Applied stress } \\
{[\mathrm{MPa}]}\end{array}$ & $\begin{array}{l}\text { Measured life } \\
{[\mathrm{h}]}\end{array}$ & $\begin{array}{l}\text { Predicted life with M-G } \\
{[\mathrm{h}]}\end{array}$ & $\begin{array}{l}\text { Predicted life with L-M } \\
{[\mathrm{h}]}\end{array}$ \\
\hline 60 & 130.92 & 124.17 & 123.48 \\
70 & 42.84 & 47.83 & 53.07 \\
80 & 31.41 & 28.49 & 25.83 \\
\hline
\end{tabular}

In addition to the M-G equation, the Larson-Miller (L-M) relationship is another method of predicting creep fracture life used widely in engineering. The relationship between the creep fracture life, applied stress and temperature is shown in eq. 4. 


$$
P_{\mathrm{LM}}=T\left(\lg t_{\mathrm{f}}+C\right) .
$$

where $P_{\mathrm{LM}}$ is the L-M parameter which is a function of applied stresses, and $T$ is temperature in Kelvin scale.

In general, the value of $C$ for the steels and other metal materials is around 20, which is applied in this work. And then the $P_{\mathrm{LM}}$ at the given temperature can be obtained. The double logarithmic relationship between the applied stress $\sigma$ and $P_{\mathrm{LM}}$ for the 429Mo ferritic stainless steel is shown in Fig. 6. The L-M relationship can be shown in eq. 5.

$$
\sigma=2.9 \times 10^{41} P_{\mathrm{LM}}^{-9.20877}
$$

The predicted creep fracture lives for the 429Mo steel according to the L-M relationship are also listed in Table 1. Meanwhile, the comparison in the predicted and measured creep fracture lives of 429Mo steel is illustrated in Fig. 7. It can be seen that the creep fracture life of 429Mo steel can be well estimated with both M-G and L-M methods. It is obvious that the M-G relationship is more suitable for the 429Mo steel because the value of $C$ in the L-M relationship can not accurately be determined in this work.

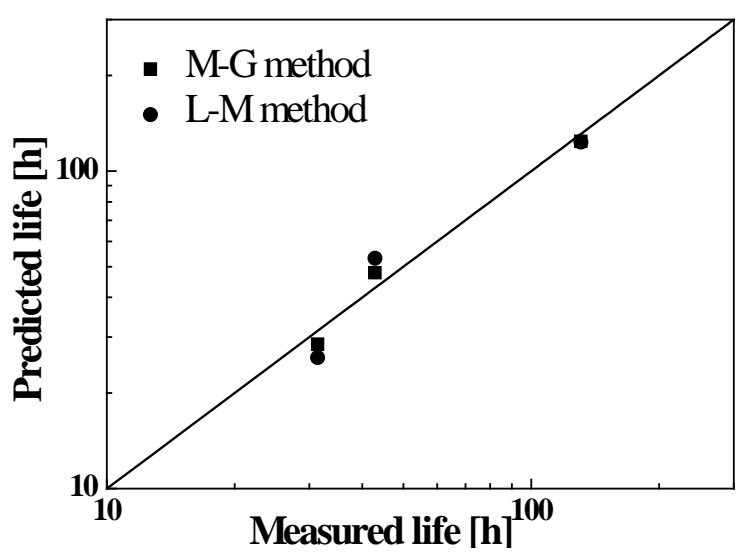

Fig. 7 Comparison in predicted and measured creep fracture lives of 429Mo steel
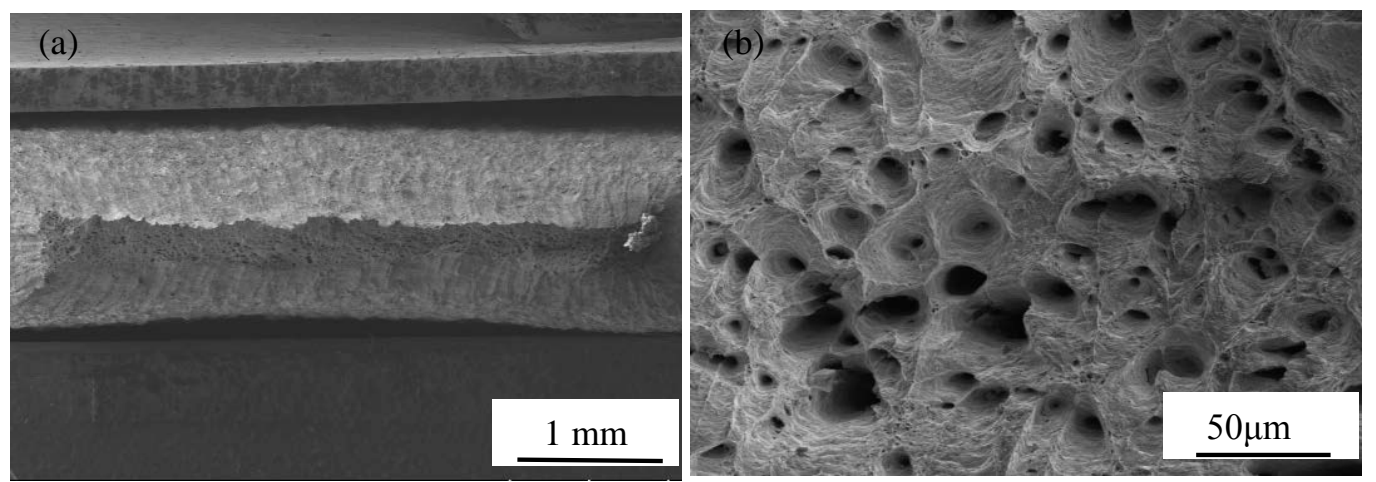

Fig. 8 SEM morphologies of creep fracture surface for $429 \mathrm{Mo}$ steel at $650^{\circ} \mathrm{C}$ and $80 \mathrm{MPa}$

Fig. 8 shows the SEM morphologies of creep fracture surface for the $429 \mathrm{Mo}$ steel at $650^{\circ} \mathrm{C}$ and $80 \mathrm{MPa}$. The remarkable necking phenomenon occurs during the creep deformation of 429Mo steel, as shown in Fig. 8(a). The morphologies of creep fracture surfaces at different stresses are very similar. There are many deeply equiaxial dimples formed due to the coalescence of microvoids where no precipitates are observed, as shown in Fig. 8(b). The fracture surfaces with the dimples 
clearly indicate that the creep fracture of $429 \mathrm{Mo}$ steel is ductile fracture with the transgranular mode.

\section{Summary}

The shape of creep curves for the 429Mo steel is similar at different applied stresses. The minimum creep rate increases and the creep fracture lives decrease with increasing the applied stress. The dislocation-climb creep mechanism plays a dominant role during the creep deformation of 429Mo steel. The precipitation of second-phase particles and the formation of stable sexangle and quadrangle dislocation networks improve the creep resistance of 429Mo steel. The creep fracture life of 429Mo steel can be predicted with both Monkman-Grant relationship and Larson-Millar relationships. The former is more accurate and more suitable for the 429Mo steel. The creep fracture surfaces with the obvious dimples indicate the creep fracture of $429 \mathrm{Mo}$ steel at $650^{\circ} \mathrm{C}$ is ductile fracture.

\section{Acknowledgments}

This work is financially supported by the National Natural Science Foundation of China (No.51134010).

\section{References}

[1] J. Shu, H.Y. Bi, X. Li, and Z. Xu, Corros. Sci.57(2012) 89-98.

[2] L. Ma, J. Han, J.Q. Shen and S.S. Hu, Acta Metall. Sin. 27(2014) 407-415.

[3] M.Y. Song, A.T. Duong, D.R. Mumm, Electro. Mater. Lett. 9(2013) 41-45.

[4] M. Gurram, K. Adepu, R.R. Pinninti and M.R. Gankidi, J. Mater. Res. Technol. 2(2013) 238-249.

[5] H.S. Seo, D.W. Yun, K.Y. Kim, Int. J. Hydrogen Energy. 38(2013) 2432-2442.

[6] H.B. Li, Z.H. Jiang, H. Feng, H.C. Zhu, B.H. Sun and Z. Li, Int. J. Miner. Metall. Mater. 20(2013) 850-860.3

[7] J.K. Kim, Y.H. Kim, H.U. Sang, J.S. Lee and K.Y. Kim, Corros. Sci. 51(2009) 2716-2723.

[8] J. Han, H.J. Li and H.G. Xu, Mater. Des. 58(2014) 518-526.

[9] Y.T. Shan, X.H. Luo, X.Q. Hu and L. Shi, J. Mater. Sci. Technol. 27(2011) 352-358.

[10] H.T. Yan, H.Y. Bi, X. Li and Z. Xu, Mater. Charact. 60(2009) 204-209.

[11]L.X. Wang, C.J. Song, F.M. Sun, L.J. Li and Q.J. Zhai, Mater. Des. 30(2009) 49-56.

[12]W.B. Dong, L. Ma, X. Zhang, H.F. Yu and L.Z. Jiang, Baosteel Tech. Res. 8(2014) 3-12.

[13]J. Froitzheim, G.H. Meier and L. Niewolak, J. Power Sources. 178(2008) 163-173.

[14]Y.T. Chiu and C.K. Lin, J. Power Sources. 198(2012)149-157.

[15]Y.T. Chiu, C.K. Lin and J.C. Wu, J. Power Sources.196(2011) 2005-2012.

[16] N. E. Dowling, Mechanical Behavior of Materials, third ed., Prentice Hall, New Jersey, 2006.

[17] A.H. Osman and T.M. Nasir, J. Nucl. Mater.433 (2013) 74-79.

[18] V. Gaffard, J. Besson and A.F. Gourgues-Lorenzon, Int. J. Fracture. 133(2005)139-166. 